\title{
A Sporadic Case of Fabry Disease Involving Repeated Fever, Psychiatric Symptoms, Headache, and Ischemic Stroke in an Adult Japanese Woman
}

\author{
Jun Sawada ${ }^{1}$, Takayuki Katayama ${ }^{1}$, Kohei Kano ${ }^{1}$, Asuka Asanome ${ }^{1}$, Kae Takahashi ${ }^{1}$, \\ Tsukasa Saito ${ }^{1}$, Junko Chinda ${ }^{1}$, Naoki Nakagawa ${ }^{1}$, Nobuyuki Sato ${ }^{1}$, Takashi Kimura ${ }^{2}$, \\ Osamu Yahara ${ }^{2}$, Ken Momosaki ${ }^{3}$, Kimitoshi Nakamura ${ }^{3}$ and Naoyuki Hasebe ${ }^{1}$
}

\begin{abstract}
Fabry disease can cause various neurological manifestations. We describe the case of a Japanese woman with Fabry disease who presented with ischemic stroke, aseptic meningitis, and psychiatric symptoms. The patient had a mutation in intron 4 of her $\alpha$-galactosidase A gene, which was not detected in her family. This case suggests that Fabry disease should be considered in young patients who exhibit central nervous system symptoms such as ischemic stroke, even if there is no family history of the condition. The episodes of aseptic meningitis and stroke experienced by our patient suggest that persistent inflammation might be the mechanism underlying Fabry disease.
\end{abstract}

Key words: Fabry disease, ischemic stroke, aseptic meningitis, psychiatric symptom, chronic inflammation, sporadic

(Intern Med 54: 3069-3074, 2015)

(DOI: 10.2169/internalmedicine.54.4719)

\section{Introduction}

Fabry disease is an X-linked multisystem lysosomal storage disorder caused by mutations in the $\alpha$-galactosidase $\mathrm{A}$ (GAL) gene, which is located at Xq22 (1). It results in the progressive accumulation of neutral glycosphingolipids, mainly globotriaosylceramide, in various organs. The clinical symptoms of Fabry disease include renal dysfunction, cardiac disease (especially left ventricular hypertrophy), cutaneous angiokeratomas, corneal dystrophy, hypohidrosis, gastrointestinal conditions, neuropathic pain, and neurological disorders (2). Symptoms of the disease are seen in both hemizygous males and heterozygous females $(3,4)$. We herein report a sporadic case of Fabry disease involving aseptic meningitis, ischemic stroke, and psychiatric symptoms in an adult Japanese woman.

\section{Case Report}

The patient was a Japanese woman who had been aware of limb pain from the ages of 9 to 15 and who had experienced a hallucinatory/delusional state after the delivery of her daughter at the age of 27. Occasional fevers of unknown origin subsequently emerged. She was admitted to a psychiatric hospital after exhibiting delusional and violent behavior at the age of 29. She received psychological treatment, but her delusions persisted. She was re-admitted to another psychiatric hospital due to the exacerbation of her psychiatric symptoms at the age of 39 . Her psychiatric symptoms improved after electroconvulsive therapy, but she subsequently developed a high fever, a throbbing headache, and dizziness. No nausea, vomiting, or nuchal stiffness was observed. Her Mini-Mental State Examination score was 20 (date: -1,

\footnotetext{
${ }^{1}$ Division of Cardiology, Nephrology, Pulmonology, and Neurology, Department of Internal Medicine, Asahikawa Medical University, Japan, ${ }^{2}$ Department of Neurology, National Hospital Organization Asahikawa Medical Center, Japan and ${ }^{3}$ Department of Pediatrics, Graduate School of Medical Science, Kumamoto University, Japan

Received for publication December 17, 2014; Accepted for publication April 5, 2015

Correspondence to Dr. Jun Sawada, sawajun@ asahikawa-med.ac.jp
} 
Table. Laboratory Findings.

\begin{tabular}{|c|c|c|c|}
\hline \multicolumn{2}{|c|}{ Age at time of the assessment } & 39 & 42 \\
\hline \multicolumn{4}{|c|}{ Urinalysis } \\
\hline \multicolumn{2}{|l|}{ Protein } & negative & negative \\
\hline \multicolumn{2}{|l|}{ Occult blood } & negative & negative \\
\hline \multicolumn{4}{|l|}{ Peripheral blood } \\
\hline White blood cells & $(/ \mu \mathrm{L})$ & 8,100 & 6,390 \\
\hline Red blood cells & $\left(\times 10^{4} / \mu \mathrm{L}\right)$ & 281 & 427 \\
\hline Hemoglobin & $(\mathrm{g} / \mathrm{dL})$ & 8.2 & 12.6 \\
\hline Platelet count & $\left(\times 10^{4} / \mu \mathrm{L}\right)$ & 48.4 & 39.6 \\
\hline \multicolumn{4}{|l|}{ Blood chemistry } \\
\hline Total protein & $(g / d L)$ & 7.1 & 8.6 \\
\hline Albumin & $(\mathrm{g} / \mathrm{dL})$ & 3.6 & 4.6 \\
\hline Urea nitrogen & $(\mathrm{mg} / \mathrm{dL})$ & 11.1 & 11.0 \\
\hline Creatinine & $(\mathrm{mg} / \mathrm{dL})$ & 0.7 & 0.47 \\
\hline C-reactive protein & $(\mathrm{mg} / \mathrm{dL})$ & 1.5 & 0.20 \\
\hline Total bilirubin & $(\mathrm{mg} / \mathrm{dL})$ & 0.3 & 0.5 \\
\hline HDL cholesterol & $(\mathrm{mg} / \mathrm{dL})$ & 59.4 & 54.2 \\
\hline LDL cholesterol & $(\mathrm{mg} / \mathrm{dL})$ & 76.0 & 139.4 \\
\hline Triglycerides & $(\mathrm{mg} / \mathrm{dL})$ & 59.0 & 87.0 \\
\hline Fasting glucose & $(\mathrm{mg} / \mathrm{dL})$ & 102.0 & 92.0 \\
\hline Hemoglobin A1c (J) & $(\%)$ & 4.4 & 5.2 \\
\hline Immunoglobulin $\mathrm{G}$ & $(\mathrm{mg} / \mathrm{dL})$ & $1,733.0$ & $2,078.7$ \\
\hline Immunoglobulin $\mathrm{M}$ & $(\mathrm{mg} / \mathrm{dL})$ & 113.0 & 125.9 \\
\hline Immunoglobulin A & $(\mathrm{mg} / \mathrm{dL})$ & 289.0 & 235.8 \\
\hline \multicolumn{4}{|l|}{ Cerebrospinal fluid } \\
\hline \multicolumn{2}{|l|}{ Appearance } & translucent & n.d. \\
\hline Pressure & $\mathrm{mmH}_{2} \mathrm{O}$ & 150 & n.d. \\
\hline Cells & $/ \mu \mathrm{L}$ & 10 & n.d. \\
\hline Neutrophils & $(\%)$ & 7 & n.d. \\
\hline Lymphocytes & $(\%)$ & 93 & n.d. \\
\hline Protein & $(\mathrm{mg} / \mathrm{dL})$ & 64.2 & n.d. \\
\hline Immunoglobulin $\mathrm{G}$ & $(\mathrm{mg} / \mathrm{dL})$ & 9.2 & n.d. \\
\hline \multicolumn{2}{|c|}{ Immunoglobulin $\mathrm{G}$ index } & 0.657 & n.d. \\
\hline Glucose & $(\mathrm{mg} / \mathrm{dL})$ & 49.0 & n.d. \\
\hline (Serum glucose) & $(\mathrm{mg} / \mathrm{dL})$ & $(102.0)$ & n.d. \\
\hline
\end{tabular}

HDL: high-density lipoprotein, LDL: low-density lipoprotein, JDS: Japan Diabetes Society, n.d.: not determined

place: -2 , calculation: -5 , recall of name: -1 , and composition: -1). A laboratory examination revealed increased serum levels of C-reactive protein $(1.5 \mathrm{mg} / \mathrm{dL})$ and immunoglobulin $\mathrm{G}$ (IgG) (1,733.0 mg/dL), anemia (red blood cells: $281 \times$ $10^{4} / \mu \mathrm{L}$, hemoglobin: $8.2 \mathrm{~g} / \mathrm{dL}$ ), and an elevated platelet count $\left(48.4 \times 10^{4} / \mu \mathrm{L}\right)$ (Table). A cerebrospinal fluid (CSF) analysis detected mild mononuclear-dominant pleocytosis $(10$ cells $/ \mu \mathrm{L})$ and an elevated protein level $(64.2 \mathrm{mg} / \mathrm{dL})$ (Table). Bacterial, fungal, and mycobacterial cultures of the patient's CSF were all negative. In addition, polymerase chain reaction-based tests for the herpes simplex and herpes zoster viruses were negative, and no malignant cells were detected during a cytological examination. Brain magnetic resonance imaging (MRI) revealed mild frontal lobe atrophication, but did not detect any focal lesions. ${ }^{99 m}$ TC-ECD single-photon emission computed tomography revealed mild bilateral reductions in cerebral blood flow (Fig. 1). Electroencephalography showed a basic $\alpha$ wave rhythm, accompanied by a moderate number of $\theta$ waves (Fig. 2). The administration of acyclovir and globulin did not markedly improve the patient's symptoms. About a year later, her fever improved spontaneously. However, at 42 years of age she became aware of numbness in her left upper and lower extremities and was admitted to our hospital. A neurological examination demonstrated left hemisensory hypesthesia and dysesthesia. No other neurological symptoms were observed. Diffusion-weighted images of the brain obtained on admission showed a hyperintense lesion in the right thalamus, which was suggestive of a recent cerebral infarction (Fig. 3). Fluid attenuated inversion recovery (FLAIR) images of the brain showed mild atrophication of the bilateral hippocampus and frontal lobe. Magnetic resonance angiography of the brain did not detect any abnormalities in the intracranial arteries (Fig. 3). A blood cell count found that the patient's platelet count was slightly elevated $\left(39.6 \times 10^{4} / \mu \mathrm{L}\right)$, and a blood biochemical analysis detected slightly increased serum levels of low-density lipoprotein cholesterol $(139.4 \mathrm{mg} / \mathrm{dL})$ and $\operatorname{IgG}(2,078.7 \mathrm{mg} / \mathrm{dL})$. No renal dysfunction or proteinuria was observed (Table). An electrocardiogram revealed left ventricular hypertrophy (Fig. 4A), and echocardiography detected diffuse hypertrophy of the left ventricle and akinesis of the inferior basal wall (Fig. 4B). The administration of edaravone and clopidogrel was initiated, but the patient's sensory disturbances continued. A leukocyte enzyme assay detected reduced $\alpha$-GAL activity (11.9 Agal U, cut-off value: <20 Agal $U$ ), and a gene analysis revealed the presence of a heterozygous mutation in intron 4 of the $\alpha-G A L$ gene (IVS4-1G>A). However, genetic analyses of the patient's parents and daughter did not detect this mutation. The patient was therefore diagnosed with sporadic Fabry disease. No cutaneous angiokeratomas, corneal dystrophy, hypohidrosis, or gastrointestinal disorders were observed. The patient was initially treated with agalsidase- $\alpha$, but this was subsequently stopped due to fatigue. She currently takes clopidogrel and bisoprolol, and no new neurological manifestations, such as strokes, or a worsening of her psychiatric symptoms have occurred to date.

\section{Discussion}

Fabry disease affects both the peripheral nervous system and the central nervous system (CNS). CNS involvement is considered to be a major complication of Fabry disease, as are renal and cardiac involvement. The clinical CNS symptoms of Fabry disease include ischemic strokes, hearing problems, psychiatric disorders, and cognitive impairment (5). Strokes are one of the major complications of classical Fabry disease. A study of patients aged 18-55 years who had suffered cryptogenic strokes detected a high prevalence of Fabry disease (5\% of males and 3\% of females) (6). In patients with Fabry disease, strokes tend to occur more frequently in the vertebrobasilar system than in the carotid circulation (6). In Fabry disease, dolichoectasia of the large arteries is considered to be associated with hypertension and the formation of intravascular deposits of globotriaosylceramide in the endothelial cells, which leads to the progressive occlusion of the long perforating arteries in the vertebrobasilar territory. In addition, cardioembolic infarctions have been reported to occur in combination with hypertrophic cardiomyopathy, valvular disease, and arrhythmia, and atherosclerosis related to end-stage renal failure is 


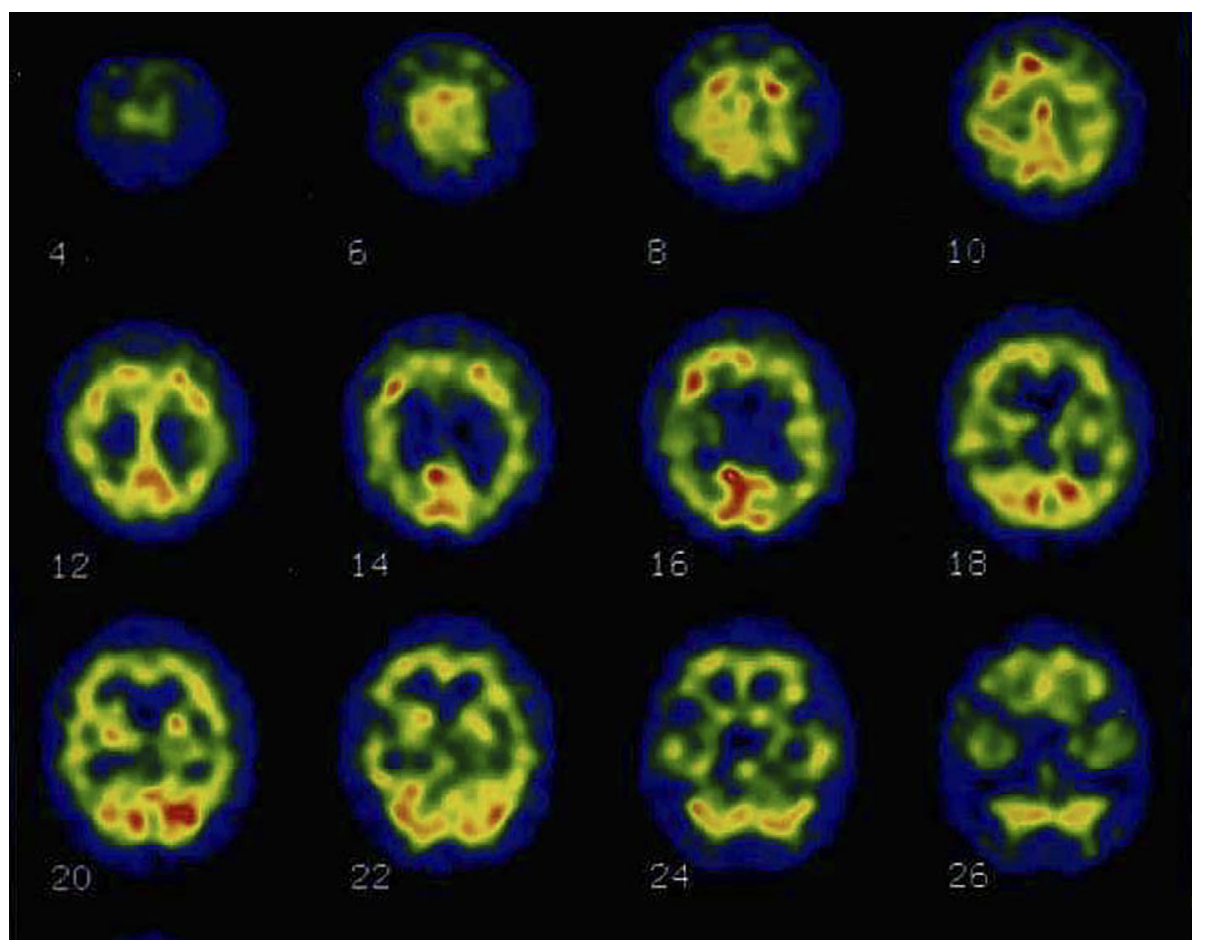

Figure 1. ${ }^{99 m}$ Tc ECD single- photon emission computed tomography revealed mild bilateral reductions in cerebral blood flow.

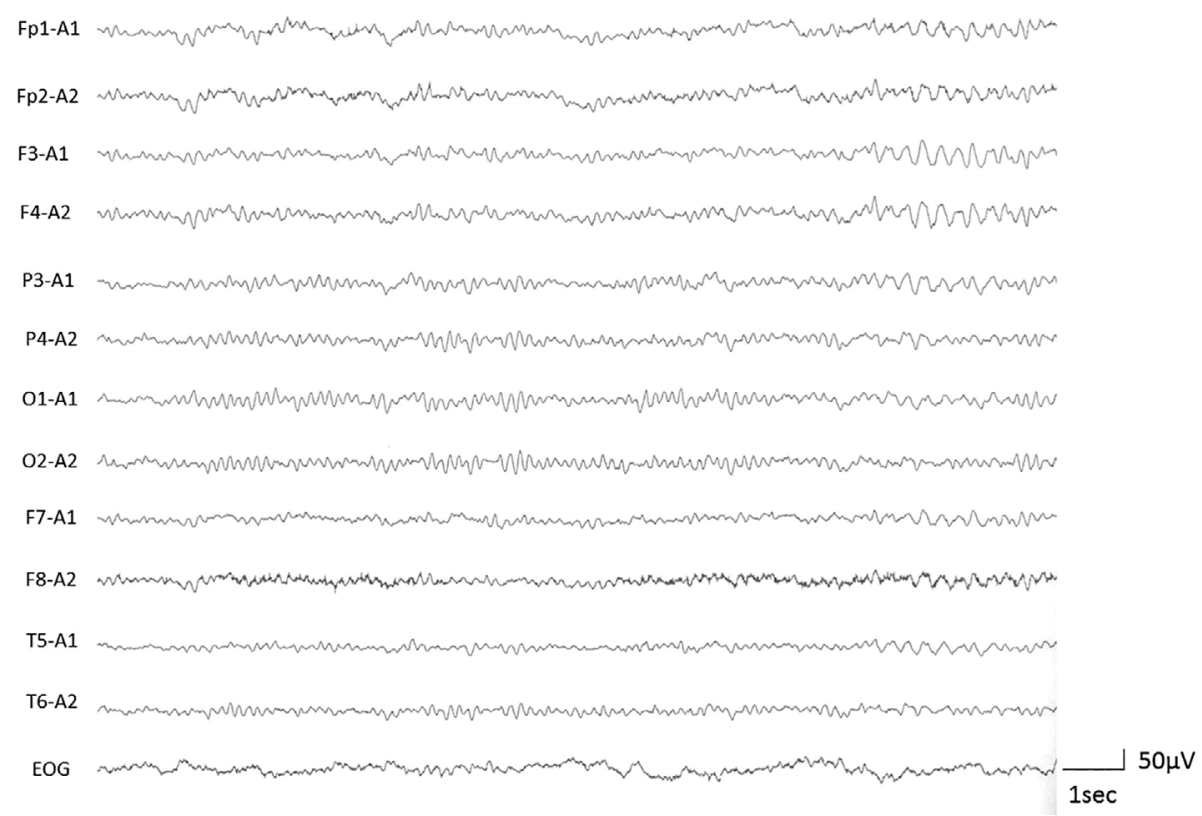

Figure 2. Electroencephalography detected a basic $\alpha$ wave rhythm, accompanied by a moderate number of $\theta$ waves.

also seen in Fabry disease (7).

The development of aseptic meningitis in a patient with Fabry disease has been reported in a number of cases (7-12). In most of these cases, the patients suffered multiple or recurrent strokes, which exhibited a vertebrobasilar predominance. The high frequency of strokes in this subgroup suggests that aseptic meningitis and stroke are related in Fabry disease $(13,14)$.
CSF pleocytosis in Fabry disease is assumed to be caused by the abnormal accumulation of sphingolipids within the pia, arachnoid membranes, and choroidal stroma (15). A recent study detected significant associations between cerebral lesions and genotypic polymorphisms affecting interleukin-6, endothelial nitric oxide synthase, factor $\mathrm{V}$, or protein $\mathrm{Z}$, which are involved in inflammation, vascular wall biology, and the clotting mechanism (16). These findings suggest that 

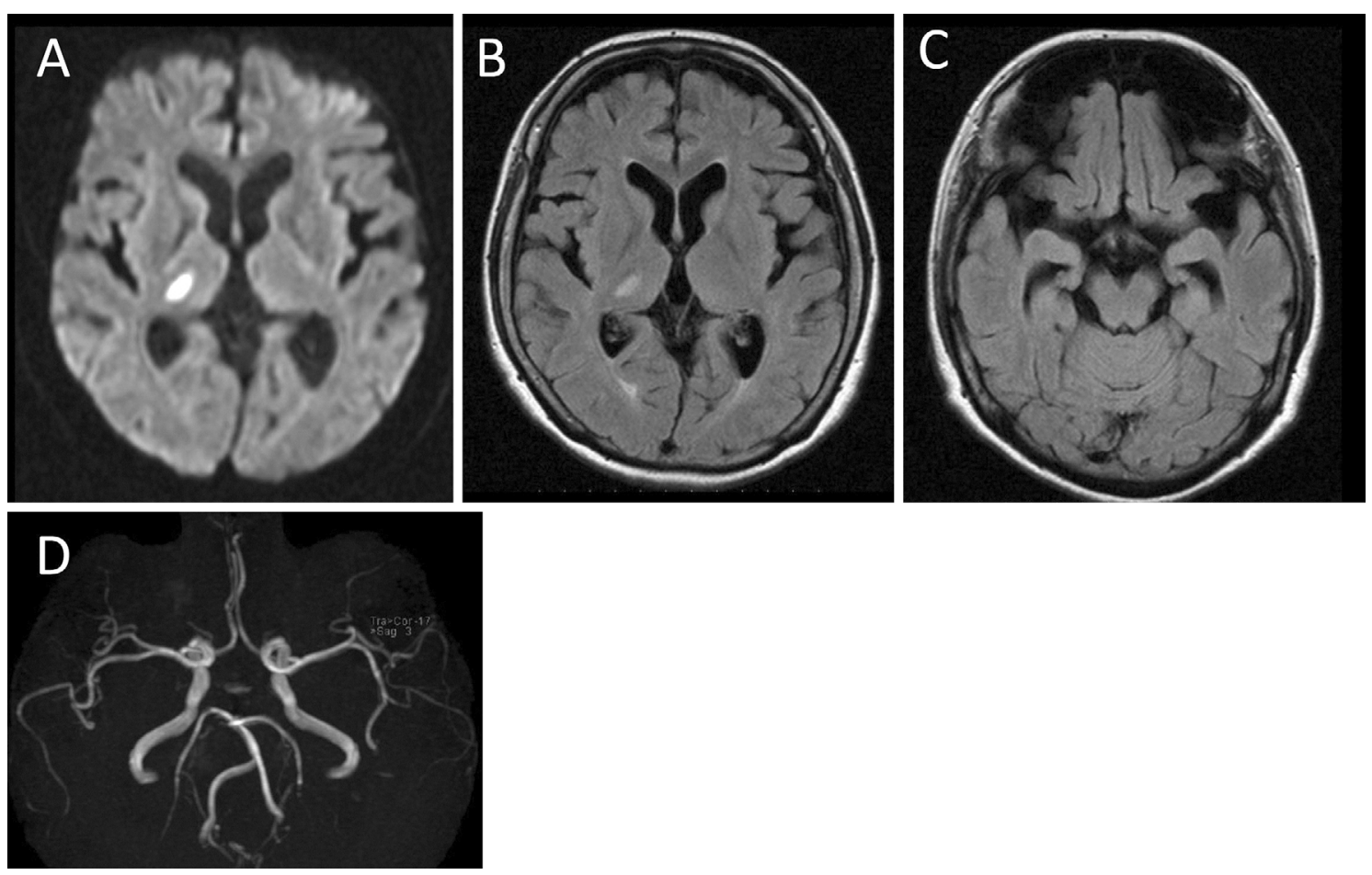

Figure 3. Magnetic resonance imaging (MRI) and magnetic resonance angiography (MRA) findings of the patient's brain on admission. A: Diffusion-weighted images showing a hyperintense lesion in the right thalamus. B, C: Fluid attenuated inversion recovery images showing mild atrophication of the bilateral hippocampus and frontal lobe. D: MRA did not detect any intracranial artery abnormalities.

the above mentioned proteins influence the cerebral vasculopathy seen in Fabry disease.

Another important feature of Fabry disease is its associated psychiatric symptoms. A single case series of 33 men with Fabry disease showed that $18 \%$ of them had psychiatric disorders, with depression being the most common condition (17). Fabry disease has been reported to produce a confused state and psychotic syndromes in rare cases (17-20). One of the latter reports suggested that the co-occurrence of Fabry disease and schizophrenia-like psychiatric symptoms was coincidental (20). However, in the present case, the patient's psychiatric symptoms and fever emerged simultaneously; suggesting that aseptic meningoencephalitis caused by Fabry disease might have induced the patient's psychiatric symptoms. In a previous study (19), it was suggested that thalamic lesions might be related to the pathogenesis of psychotic symptoms in Fabry disease. However, our patient experienced psychiatric symptoms before she suffered a thalamic infarction. Thus, psychiatric symptoms can emerge in Fabry disease in the presence or absence of thalamic lesions. When a younger patient presents with psychiatric symptoms accompanied by a fever of unknown origin, left ventricular hypertrophy, renal dysfunction, minor stroke and/or sensory disturbance, then Fabry disease should be considered in the differential diagnosis.

To date, more than 600 mutations in the human $\alpha-\mathrm{GAL}$ gene have been found to cause Fabry disease. About $70 \%$ of them are missense or nonsense mutations, whereas the re- mainder consist of splicing regulatory, or small or gross insertion/deletion mutations (21). The first report of a Fabry disease-associated mutation in intron 4 of the $\alpha$-GAL gene (IVS4-1G>A), as was detected in our case, was published in 2006 (22). Such mutations are usually inherited, and cases involving de novo mutations are rare (23). However, cases of Fabry disease involving de novo mutations have been reported in various countries $(21,23-32)$. In an analysis of Japanese pedigrees associated with reduced $\alpha$-GAL activity, 5 out of 93 pedigrees $(5.6 \%)$ were found to possess de novo mutations (33). In addition to the present study, there have been two detailed case reports on sporadic Fabry disease in Japanese patients. One case involved a 16-year-old man who presented with angiokeratoma, limb neuropathic pain, anhidrosis, and mild corneal opacity and who exhibited a mutation in intron 5 of the $\alpha-G A L$ gene (IVS5+1 A>G) (34). Another case involved a 42-year old woman who displayed proteinuria and mild hypohidrosis and possessed a Pro210 Ser mutation (35). To the best of our knowledge, our report is the first to describe a case of sporadic Fabry disease in a patient who presented with aseptic meningitis, ischemic stroke, and psychiatric symptoms.

The mutation in intron 4 of the $\alpha-G A L$ gene (IVS4-1G> A) that was detected in the present case resulted in the classical Fabry disease phenotype (22). However, the patient's CNS symptoms were more marked than the symptoms associated with other organs. Heterozygous female patients with Fabry disease can present with various clinical manifesta- 


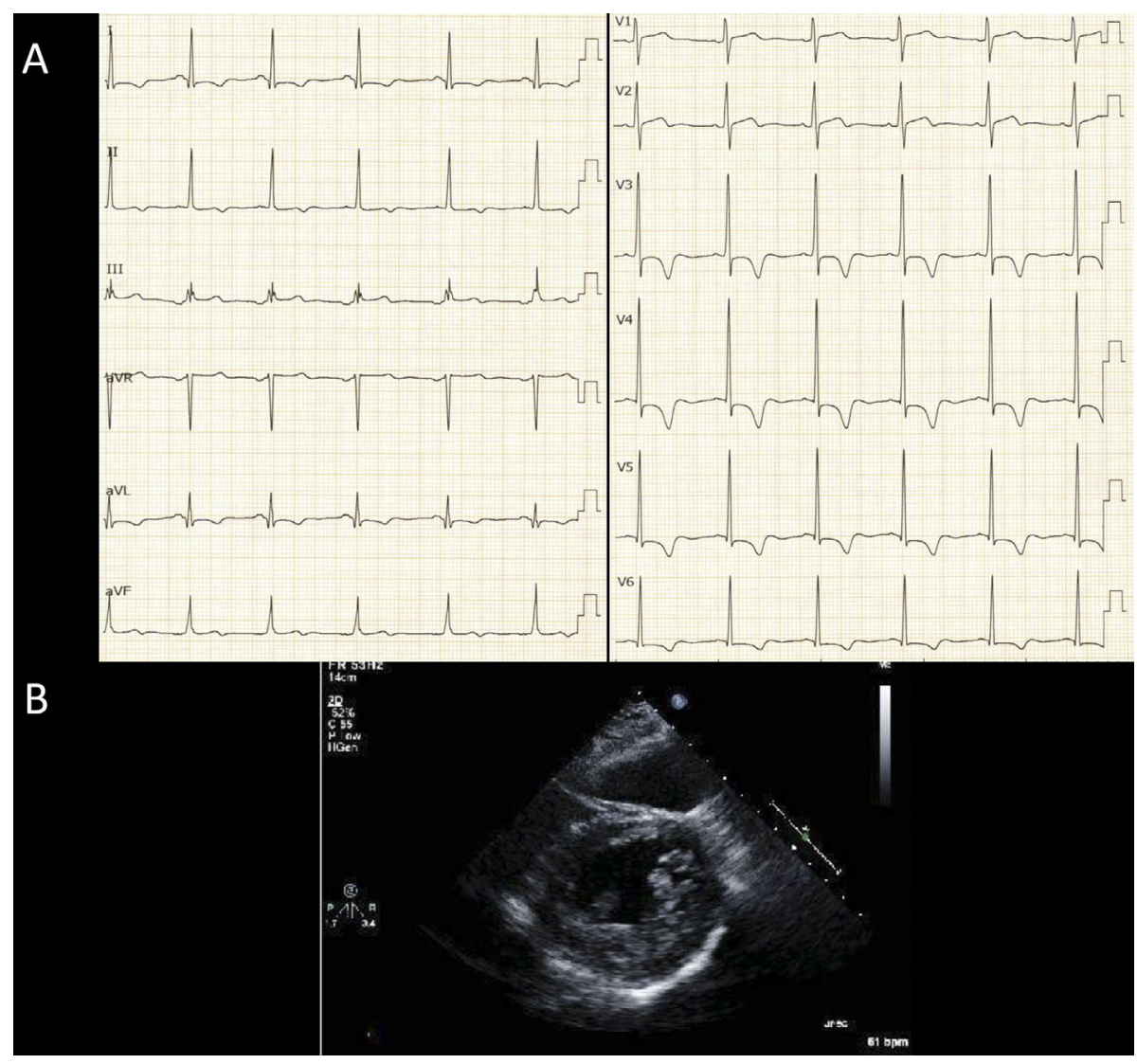

Figure 4. Twelve-lead electrocardiogram (ECG) (A) and transthoracic echocardiography (TTE) (B) obtained on admission. A: The twelve-lead ECG revealed a normal sinus rhythm and left ventricular hypertrophy. ST-T changes that were indicative of left ventricular strain were also noted. B: On the short-axis view, TTE showed left ventricular hypertrophy, especially in the posterolateral lesion.

tions (36), and it is important to keep in mind that atypical clinical manifestations can be observed in such patients. The pathogenic mechanism of the CNS symptoms seen in Fabry disease might be elucidated by examining the relationship between $\alpha$-GAL gene mutations and CNS symptoms.

In conclusion, we reported a case of sporadic Fabry disease involving a patient that presented with psychiatric symptoms, aseptic meningitis, and ischemic stroke. Fabry disease can present with various neurological manifestations. This case suggests that Fabry disease should be considered during the differential diagnosis of young patients who suffer cryptogenic strokes or display CNS symptoms, including aseptic meningitis or psychosis, and experience fevers of unknown origin, even if they have no family history of Fabry disease.

The authors state that they have no Conflict of Interest (COI).

\section{Acknowledgement}

The authors thank Dr. K. Tabata of Asahikawa Keisenkai Hospital for providing the patient's psychiatric treatment and Professor Y. Makita of Asahikawa Medical University for providing genetic counseling to the patient and her family.

\section{References}

1. Spada M, Pagliardini S, Yasuda M, et al. High incidence of lateronset fabry disease revealed by newborn screening. Am J Hum Genet 79: 31-40, 2006.

2. Mehta A, Ricci R, Widmer U, et al. Fabry disease defined: baseline clinical manifestations of 366 patients in the Fabry Outcome Survey. Eur J Clin Invest 34: 236-242, 2004.

3. Wilcox WR, Oliveira JP, Hopkin RJ, et al. Females with Fabry disease frequently have major organ involvement: lessons from the Fabry Registry. Mol Genet Metab 93: 112-128, 2008.

4. MacDermot KD, Holmes A, Miners AH. Anderson-Fabry disease: clinical manifestations and impact of disease in a cohort of 98 hemizygous males. J Med Genet 38: 750-760, 2001.

5. Fellgiebel A, Muller MJ, Ginsberg L. CNS manifestations of Fabry's disease. Lancet Neurol 5: 791-795, 2006.

6. Rolfs A, Böttcher T, Zschiesche M, et al. Prevalence of Fabry disease in patients with cryptogenic stroke: a prospective study. The Lancet 366: 1794-1796, 2005.

7. Lidove O, Chauveheid MP, Caillaud C, et al. Aseptic meningitis and ischaemic stroke in Fabry disease. Int J Clin Pract 63: 16631667, 2009.

8. Dubost JJ, Viallard IL, Sauvezie B. Chronic meningitis in Fabry's disease. J Neurol Neurosurg Psychiatry 48: 714-715, 1985.

9. Uyama E, Ueno N, Uchino M, et al. Headache associated with aseptic meningeal reaction as clinical onset of Fabry's disease. Headache 35: 498-501, 1995.

10. Perrot $X$, Nighoghossian N, Derex L, et al. [Vertebro-basilar 
ischemic strokes and aseptic meningitis, late complications of Fabry's disease]. Rev Neurol (Paris) 158: 596-598, 2002 (in French, Abstract in English).

11. Schreiber W, Udvardi A, Kristoferitsch W. Chronic meningitis and lacunar stroke in Fabry disease. J Neurol 254: 1447-1449, 2007.

12. Lidove O, Chauveheid MP, Benoist L, Alexandra JF, Klein I, Papo T. Chronic meningitis and thalamic involvement in a woman: Fabry disease expanding phenotype. J Neurol Neurosurg Psychiatry 78: 1007, 2007.

13. Eng CM, Fletcher J, Wilcox WR, et al. Fabry disease: baseline medical characteristics of a cohort of 1765 males and females in the Fabry Registry. J Inherit Metab Dis 30: 184-192, 2007.

14. Linhart A, Kampmann C, Zamorano JL, et al. Cardiac manifestations of Anderson-Fabry disease: results from the international Fabry outcome survey. Eur Heart J 28: 1228-1235, 2007.

15. Lou HO, Reske-Nielsen E. the central nervous system in Fabry's disease. A clinical, pathological, and biochemical investigation. Arch Neurol 25: 351-359, 1971.

16. Altarescu G, Moore DF, Schiffmann R. Effect of genetic modifiers on cerebral lesions in Fabry disease. Neurology 64: 2148-2150, 2005.

17. Grewal RP. Psychiatric disorders in patients with Fabry's disease. Int J Psychiatry Med 23: 307-312, 1993.

18. Liston EH, Levine MD, Philippart M. Psychosis in Fabry disease and treatment with phenoxybenzamine. Arch Gen Psychiatry 29: 402-403, 1973.

19. Shen YC, Haw-Ming L, Lin CC, Chen CH. Psychosis in a patient with Fabry's disease and treatment with aripiprazole. Prog Neuropsychopharmacol Biol Psychiatry 31: 779-780, 2007.

20. Gairing S, Wiest R, Metzler S, Theodoridou A, Hoff P. Fabry's disease and psychosis: causality or coincidence? Psychopathology 44: 201-204, 2011.

21. Li H, Zhou FS, Wang ZX, et al. Novel G144D mutation of the GLA gene in a Chinese patient with Fabry disease. J Dermatol 41: 456-457, 2014.

22. Shabbeer J, Yasuda M, Benson SD, Desnick RJ. Fabry disease: identification of 50 novel alpha-galactosidase A mutations causing the classic phenotype and three-dimensional structural analysis of 29 missense mutations. Hum Genomics 2: 297-309, 2006.

23. Iemolo F, Pizzo F, Albeggiani G, et al. De novo mutation in a male patient with Fabry disease: a case report. BMC Res Notes 7: 11, 2014.

24. Bernstein HS, Bishop DF, Astrin KH, et al. Fabry disease: six gene rearrangements and an exonic point mutation in the alphagalactosidase gene. J Clin Invest 83: 1390-1399, 1989.
25. Eng CM, Niehaus DJ, Enriquez AL, Burgert TS, Ludman MD, Desnick RJ. Fabry disease: twenty-three mutations including sense and antisense $\mathrm{CpG}$ alterations and identification of a deletional hot-spot in the alpha-galactosidase A gene. Hum Mol Genet 3: 1795-1799, 1994.

26. Madsen KM, Hasholt L, Sorensen SA, Fermer ML, Dahl N. Two novel mutations (L32P) and (G85N) among five different missense mutations in six Danish families with Fabry's disease. Hum Mutat 5: 277-278, 1995.

27. Redonnet-Vernhet I, Ploos van Amstel JK, Jansen RP, Wevers RA, Salvayre R, Levade $T$. Uneven $X$ inactivation in a female monozygotic twin pair with Fabry disease and discordant expression of a novel mutation in the alpha-galactosidase A gene. J Med Genet 33: 682-688, 1996.

28. Davies JP, Eng CM, Hill JA, et al. Fabry disease: fourteen alphagalactosidase A mutations in unrelated families from the United Kingdom and other European countries. Eur J Hum Genet 4: 219224, 1996.

29. Rodriguez-Mari A, Coll MJ, Chabas A. Molecular analysis in Fabry disease in Spain: fifteen novel GLA mutations and identification of a homozygous female. Hum Mutat 22: 258, 2003.

30. Brokalaki EI, Hentschke M, Grabbe S, Jansen T. Fabry disease in a female patient due to a de novo point mutation at position 691 of exon 5. Eur J Med Res 11: 306-308, 2006.

31. Paull LS, Lipinski MJ, Wilson WG, Lipinski SE. Female with Fabry disease unknowingly donates affected kidney to sister: a call for pre-transplant genetic testing. JIMD Rep 4: 1-4, 2012.

32. Cai ZY, Zhang YK, Wang SX, Fang QY, Chen YQ. Diffuse thin glomerular basement membrane in association with Fabry disease in a Chinese female patient. Nephrol Dial Transplant 26: 38133816, 2011.

33. Kobayashi M, Ohashi T, Eto Y, Ida H. [A gene analysis of Fabry disease: the pitfall]. The Lipid 24: 302-303, 2013 (in Japanese).

34. Kashihara T, Uchida D, Oeda T, et al. [A novel gene mutation: A sporadic case of classical Fabry disease with an abnormality of splice acceptor site in intron 5]. Nihon Naibunpigakkai Zasshi (Folia Endocrinologica Japonica) 74: 197, 1998 (in Japanese).

35. Takahashi N, Kasuno K, Tukimura T, et al. [A sporadic heterozygous female case of Fabry disease with a novel mutation discovered by health examination]. Nihon Jinzou Gakkaishi (The Japanese journal of Nephrology) 55: 1194, 2013 (in Japanese).

36. Kobayashi M, Ohashi T, Sakuma M, Ida H, Eto Y. Clinical manifestations and natural history of Japanese heterozygous females with Fabry disease. J Inherit Metab Dis 31(Suppl 3): S483-S487, 2008 .

(C) 2015 The Japanese Society of Internal Medicine

http://www.naika.or.jp/imonline/index.html 